\title{
Avaliação quali-quantitativa das praças do quadrante sudeste de Votuporanga - SP
}

Qualitative and quantitative evaluation of the squares of the southeastern quadrant of Votuporanga - SP

Evaluación cuali-cuantitativa de las plazas del cuadrante sudeste de Votuporanga - SP

Andrea Penha Gregório Vasconcelos Mestre em Ciências Ambientais pela Universidade Brasil, Brasil andreapenha@gmail.com

\section{Gisele Herbst Vazquez}

Professora Doutora Universidade Brasil, Brasil gisele.vazquez@universidadebrasil.edu.br 


\section{RESUMO}

As praças são espaços públicos urbanos livres de edificações que têm a função de promover o bem-estar à população, proporcionando a prática de esportes, lazer, incentivo à inclusão social e a expressão cultural. No cotidiano urbano moderno, a praça é um local de escape e, para que isso ocorra, é necessário que todo o contexto esteja harmonioso e conservado, como os bancos, caminhos, iluminação e outros equipamentos, além da cobertura vegetal, de forma a atrair a população e proporcionar conforto para seus frequentadores. Porém, muitas vezes, seu mau estado de conservação acarreta sua subutilização, afasta as pessoas e cria um círculo vicioso de degradação. 0 objetivo desta pesquisa foi realizar uma análise quali-quantitativa da situação das 24 praças do quadrante Sudeste de Votuporanga-SP, dos seus elementos arquitetônicos e da arborização a fim de diagnosticar esses espaços e subsidiar futuras adequações municipais para melhor atender à população. Em julho de 2017, foram realizadas visitas in loco e concluiu-se que as praças do quadrante SE de Votuporanga-SP são de extrema importância à população adjacente, embora a maioria careça de infraestrutura e necessite de investimentos na conservação e manutenção dos seus elementos arquitetônicos e paisagísticos para promover lazer aos frequentadores de forma eficaz e satisfatória. Quanto as árvores, $75,5 \%$ são nativas, mas existe a necessidade de um maior número e diversificação de espécies.

PALAVRAS-CHAVE: Paisagismo. Áreas verdes. Áreas públicas. Arborização urbana.

\section{Abstract}

The squares are urban public spaces free of buildings that have the function of promoting well-being to the population, providing the practice of sports, leisure, encouraging social inclusion and cultural expression. In the modern urban daily life, the square is an escape point and, for this to happen, it is necessary that the whole context is harmonious and preserved, such as benches, paths, lighting and other equipment, in addition to the vegetation cover, in order to attract the population and provide comfort for its users. However, their poor state of conservation often causes their underutilization, it distances people and creates a vicious circle of degradation. The objective of this research was to perform a qualitative and quantitative analysis of the situation of the 24 squares of the Southeastern quadrant of Votuporanga-SP (Brazil), its architectural elements and the afforestation in order to diagnose these spaces and to subsidize future municipal adaptations to better serve the population. In July 2017, on-site visits were carried out and it was possible to conclude that the squares of the SE quadrant of VotuporangaSP are extremely important to the adjacent population, although most lack infrastructure and need investments in the conservation and maintenance of its architectural elements and landscaping to promote leisure to the visitors in an effective and satisfactory way. Regarding the trees, although $75.5 \%$ are native, there is a need for a greater number and diversification of species.

Key-words: Landscaping. Green areas. Public areas. Urban afforestation.

\section{Resumen}

Las plazas son espacios públicos urbanos libres de edificaciones que tienen la función de promover el bienestar a la población, proporcionando la práctica de deportes, ocio, incentivo a la inclusión social y la expresión cultural. En el cotidiano urbano moderno, la plaza es un lugar de escape $y$, para que eso ocurra, es necesario que todo el contexto esté armonioso y conservado, como los bancos, caminos, iluminación y otros equipamientos, además de la cobertura vegetal, para atraer la población y proporcionar comodidad a sus frecuentadores. Sin embargo, a menudo, su mal estado de conservación acarrea su infrautilización, aleja a las personas y crea un círculo vicioso de degradación. El objetivo de esta investigación fue realizar un análisis cuali-cuantitativo de la situación de las 24 plazas del cuadrante Sudeste de Votuporanga-SP, de sus elementos arquitectónicos y de la arborización a fin de diagnosticar esos espacios y subsidiar futuras adecuaciones municipales para atender mejor a la población. En julio de 2017 se realizaron visitas in situ y se concluyó que las plazas del cuadrante SE de Votuporanga-SP son de extrema importancia a la población adyacente, aunque la mayoría carece de infraestructura y necesita inversiones en la conservación y mantenimiento de sus elementos arquitectónicos y paisajísticos para promover el ocio a los frecuentadores de forma eficaz y satisfactoria. En cuanto a los árboles, a pesar de que el 75,5\% son nativos, existe la necesidad de un mayor número y diversificación de especies.

Palavras clave: Paisajismo. Áreas verdes. Áreas públicas. Arborización urbana. 


\section{INTRODUÇÃO}

Segundo a Organização Mundial da Saúde, a qualidade de vida indica o nível das condições básicas e suplementares do ser humano. Tais condições envolvem o bem-estar físico, mental, psicológico e emocional, os relacionamentos sociais, bem como família e amigos, a saúde, a educação, lazer e outros parâmetros que afetam a vida humana (MINAYO; HARTZ; BUSS et al., 2000).

De acordo com a Constituição Federal de 1988, o direito ao lazer está inserido nos artigos 6으, caput, artigo 70, IV, artigo 217, § 3으, e artigo 227, no capítulo dos Direitos Sociais, e este, por sua vez, no Título dos Direitos Fundamentais (BRASIL, 2016).

Com o tempo e o crescente aumento da urbanização das cidades, as relações humanas mudaram, principalmente quanto ao contato entre as pessoas, haja vista que não há mais tempo para uma conversa informal e a contemplação da natureza. Além disso, o mau estado de conservação de grande parte das praças, em várias cidades brasileiras, afastou seus frequentadores e criou um círculo vicioso de degradação (ALCÂNTARA; VAZQUEZ, 2015).

De acordo com De Angelis et al. (2005), as praças, antes tidas como locais destinados ao lazer, recreação e convivência, ao longo dos tempos, levando-se em conta os diversos aspectos que as envolvem como definição, funções, usos e concepções, sofreram significativas mudanças. Todavia, é consenso que, a despeito das transformações impostas pelo tempo, as praças ainda representam um espaço público de grande importância no cotidiano urbano.

Segundo Souza e Amorim (2013), as praças devem ser percebidas como necessárias e importantes na qualidade de vida de seus moradores, não podendo ser colocadas em segundo plano pela comunidade e poder público, pois amenizam a amplitude térmica nos centros urbanos, fixam a poeira e gases poluentes, diminuem o nível de ruídos, absorvem água, melhoram a umidade atmosférica, abrigam a fauna, promovem a cultura e a cidadania por meio de eventos e atividades cívicas, além de serem um espaço de valor estético e recreativo.

A cidade de Votuporanga-SP, de acordo com o Plano Diretor de 2006 (VOTUPORANGA, 2006), está dividida em quatro quadrantes, definidos preliminarmente com a aprovação do Plano de Desenvolvimento Integrado (PDI) em 1971 (VOTUPORANGA, 1971), e emprega o sistema cartesiano de coordenadas, identificados por sua orientação e denominados $\mathrm{NE}, \mathrm{SE}$, SO e NO, havendo em todo o município 72 praças, possuindo o quadrante sudeste (SE) 24 praças, ou $33,3 \%$ da totalidade e que representa o foco desta pesquisa.

\section{OBJETIVO}

O objetivo desta pesquisa foi realizar uma análise quali-quantitativa da situação das 24 praças do quadrante Sudeste de Votuporanga-SP, dos seus elementos arquitetônicos e da arborização a fim de diagnosticar esses espaços e subsidiar futuras adequações municipais para melhor atender à população. 
Revista Nacional de Gerenciamento de Cidades

\section{METODOLOGIA}

Votuporanga possui uma população estimada para 2017 de 92.768 habitantes (IBGE, 2017), uma área de 422,90 km² (VOTUPORANGA, 2018) e está localizada na região noroeste do Estado de São Paulo, próxima à São José do Rio Preto $(86 \mathrm{~km})$ e a cerca de $520 \mathrm{~km}$ da capital São Paulo.

Em julho de 2017 foram realizadas visitas in loco as 24 praças do quadrante SE para a execução do levantamento quali-quantitativo dos elementos arquitetônicos e a determinação das espécies vegetais arbóreas presentes (Figura 1 ).

Para a análise quantitativa dos equipamentos das praças foi feito um levantamento quanto à sua presença ou ausência, aplicando-se para isso, um roteiro de observação baseado na metodologia proposta por De Angelis, Castro e De Angelis Neto (2004).

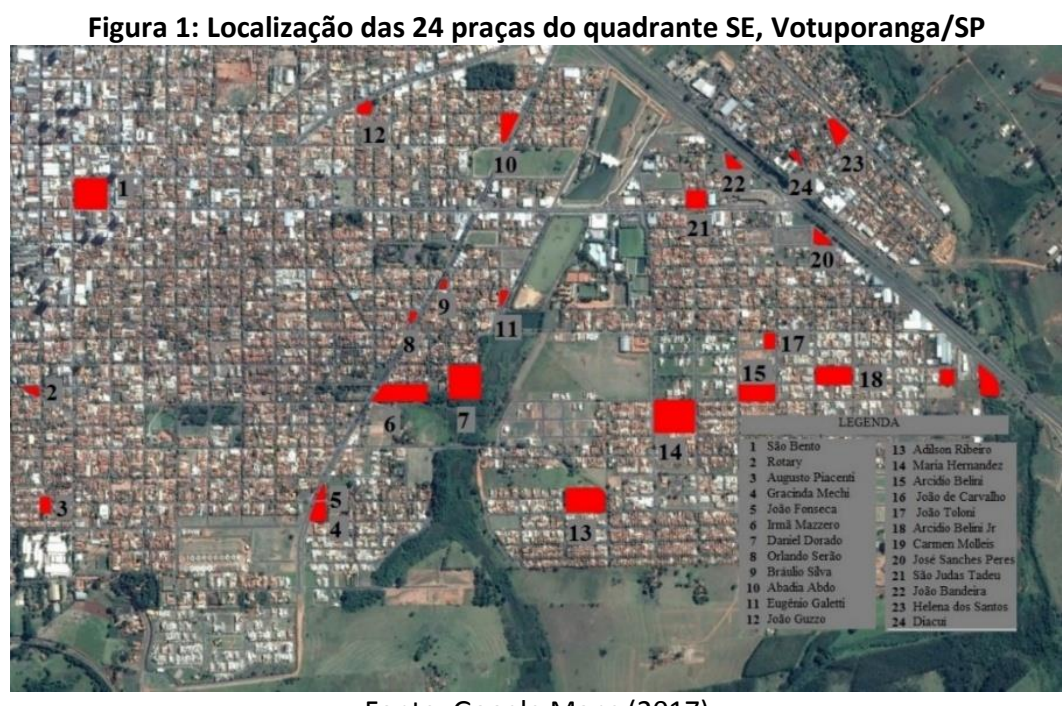

Fonte: Google Maps (2017)

Já a análise qualitativa seguiu a metodologia proposta por Alcântara e Vazquez (2015), onde cada equipamento foi avaliado quanto a vários parâmetros, como, condição de conservação, disponibilidade para uso, qualidade do material utilizado, manutenção, conforto, funcionalidade, segurança, entre outros, que atendidos ou não, geraram uma nota e um conceito (Tabela 1). 
Revista Nacional de

Gerenciamento de Cidades

Tabela 1: Avaliação qualitativa dos elementos arquitetônicos, notas e conceitos de acordo com o desempenho

\begin{tabular}{cll}
\hline NOTA & CONCEITO & PADRÃO DE DESEMPENHO DO EQUIPAMENTO \\
\hline $0-0,5$ & P & Insuficiente/não atende a nenhum critério avaliado com qualidade \\
$0,51-1,5$ & RU & Pouco suficiente/atende somente 1 ou 2 itens avaliados \\
$1,51-2,5$ & RE & Parcialmente atendido/atende menos da metade dos critérios avaliados \\
$2,51-3,5$ & B & Suficientemente atendido/atende a maioria dos critérios avaliados \\
$3,51-4,0$ & Ó & Plenamente atendido/atende todos os critérios avaliados \\
\hline
\end{tabular}

Nota: PÉSSIMO (P), RUIM (RU), REGULARES (RE), BOM (B), OTIMO (O).

Fonte: Alcântara e Vazquez (2015)

Assim, cada equipamento foi avaliado pela mesma pessoa segundo os critérios propostos por Alcântara e Vazquez (2015), de forma a evitar a subjetividade levando-se em conta os seguintes aspectos:

- $\quad$ Bancos: quantidade suficiente, material, conservação, localização (sombra/sol);

- Iluminação alta/baixa: localização, conservação, segurança, disposição da iluminação nos acessos e nas áreas de circulação, otimização dos pontos de luz em função da copa das árvores, adequação à função socioambiental do espaço, considerando a paisagem, a segurança e o impacto sobre a vegetação arbórea;

- Lixeiras: tipo, adequação da quantidade ao número de usuários, localização e distanciamento, funcionalidade, material empregado, conservação e estética;

- $\quad$ Sanitários: quantidade, disponibilidade de uso, condições de uso e conservação;

- Telefone público: disposição, disponibilidade, acessibilidade e conservação;

- Bebedouros: tipo, quantidade, limpeza e higiene, condições de uso, conservação e acessibilidade;

- $\quad$ Piso: material empregado; funcionalidade e segurança; conservação, estética, durabilidade, facilidade para manutenção, permeabilidade e acessibilidade;

- $\quad$ Traçado dos caminhos: funcionalidade, largura, manutenção, desenho e acessibilidade;

- Obras de arte/Esculturas: material, inserção no conjunto da praça, conservação e estética;

- $\quad$ Espelho d'água/Chafariz: em funcionamento, se inserido ou não no contexto da praça; conservação e manutenção da água e da estrutura;

- Coreto/Pergolados: valor histórico, funcionalidade, finalidade, conservação, design, disponibilidade de uso, se compatível com o desenho da praça;

- $\quad$ Estacionamento: localização, quantidade de vagas (atendimento às necessidades dos usuários), conservação, segurança e sombreamento;

- $\quad$ Ponto de ônibus/Ponto de táxi: se na praça, próximo ou distante de presença ou não de abrigo, conservação e atendimento às necessidades dos horários dos usuários;

- Quadra esportiva: quantidade, conservação, material empregado, disposição, cercada ou não, iluminação, acessibilidade e placas de orientação aos usuários; 


\section{Revista Nacional de}

- Equipamentos para exercícios físicos: tipo e quantidade, acesso, material empregado, conservação, adequação dos aparelhos as normas específicas e atendimento a todas as faixas etárias, acessibilidade, disposição de informações sobre sua forma de uso e segurança;

- $\quad$ Estruturas para terceira idade: conservação, material, adequação dos aparelhos as normas específicas e atendimento a faixa etária, acessibilidade, disposição de informações sobre sua forma de uso e segurança;

- Equipamentos para recreação infantil: material empregado (resistência, de fácil limpeza e pouca manutenção), conservação, adequação dos aparelhos as normas específicas e atendimento a faixa etária, área cercada, segurança e acessibilidade;

- Banca de revista: localização, estrutura, material de construção, design, estético e conservação, atendimento às necessidades dos horários dos usuários;

- Quiosques ou similar: localização, limpeza, estrutura, design, estética, atendimento às necessidades dos horários dos usuários;

- $\quad$ Espaço institucional: construções públicas para atendimento e lazer da população, sua conservação, funcionalidade e estética;

- $\quad$ Templo religioso: presença ou ausência, estado de conservação e estética;

- Paisagismo: conservação, manutenção e contribuição estética, social e ambiental;

- Localização: atendimento às necessidades dos usuários;

- $\quad$ Conservação/limpeza: frequência de manutenção e qualidade do serviço;

- $\quad$ Segurança: quantidade e frequência de policiais.

Por fim, foi realizada a identificação e o levantamento quantitativo das espécies vegetais arbóreas presentes nas praças e calculou-se a sua frequência relativa e procedência (se nativa, exótica ou exótica invasora).

\section{RESULTADOS}

Na Tabela 2 estão apresentadas o nome da praça, o bairro em que estão inseridas, suas dimensões, área de cobertura vegetal e porcentagem, além da qualidade e quantidade dos elementos arquitetônicos presentes.

Historicamente, no Brasil, pelo modelo de urbanização trazido pelos portugueses, implantavam-se igrejas ou edifícios públicos importantes em uma área, que após vegetada, passava a constituir uma praça (MARX, 1980).

Em Votuporanga, esse modelo de implantação pode ser percebido em uma das praças analisadas (Abadia Abdo), havendo neste local um Espaço Institucional - o Teatro Municipal da cidade - embora esta área não possua os demais complementos paisagísticos que caracterizam uma praça em toda a sua funcionalidade, principalmente quanto a vegetação, que é inexistente. As demais praças, por sua vez, não seguiram esse modelo, sendo resultantes das confluências dos caminhos e remanescentes das ocupações dos lotes. 


\section{Revista Nacional de}

Das 24 praças analisadas, sete estão ao lado de avenidas de grande movimento e ruído, além de terem seus acessos dificultados e perigosos, ou seja, a Avenida Vale do Sol (João Guzzo), a Avenida Pansani (Gracinda Lopes Mechi, João Fonseca, Orlando Serão e Bráulio Silva) e Avenida José Marão Filho, marginal da Rodovia Estadual 320 (José Sanchez Peres Junior e João Bandeira), fazendo com que suas principais funções não sejam atendidas, ou seja, o lazer, o descanso, a tranquilidade e o contato com a natureza.

Tabela 2: Praças do quadrante SE, bairro, dimensões, área de cobertura vegetal e porcentagem, qualidade e quantidade dos elementos arquitetônicos presentes. Votuporanga -SP, 2017

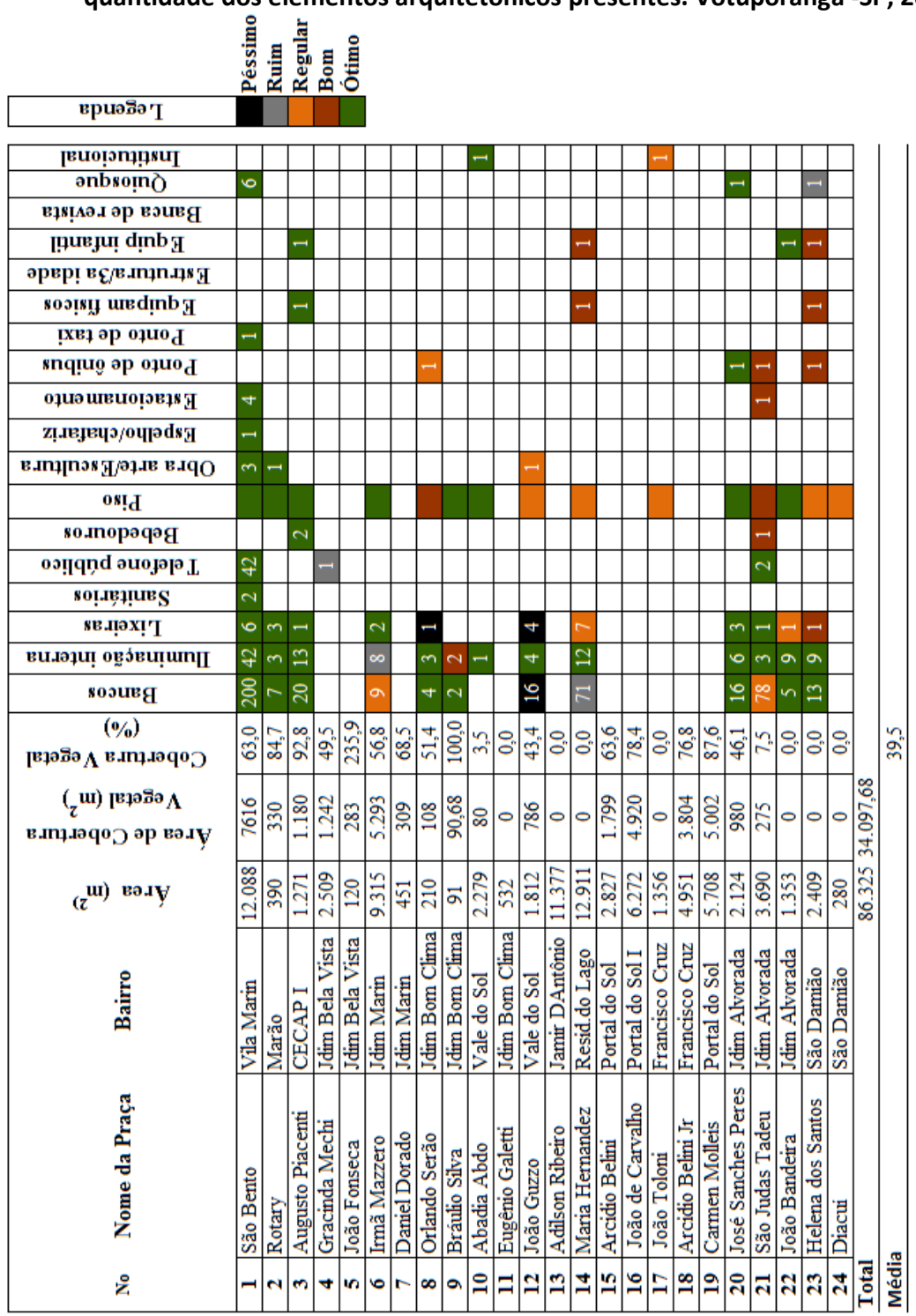

Doze praças, ou $50 \%$ do quadrante $\mathrm{SE}$, contam com bancos de concreto, com e sem encosto, estando $66,7 \%$ em bom estado de conservação (Figura 2a) e 16,7\% sem conservação e 


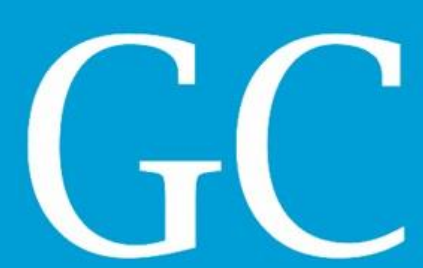

Revista Nacional de

manutenção (Figura 2b). De modo geral, nas praças com bancos, a quantidade e o posicionamento são adequados, havendo unidades a pleno sol e a sombra, porém, em duas praças (João Bandeira e Irmã Maria Ignez Mazzero), seu número é insuficiente para atender a demanda local

A iluminação está presente em 13 praças (54\%) sendo 50\% em bom estado de conservação, havendo postes altos (Figura 2c) e baixos (Figura 2d), proporcionando segurança aos usuários, embora ainda exista um número elevado de praças sem iluminação.

Figura 2: (a) Praça São Bento - bancos conservados; (b) Praça João Guzzo - bancos sem conservação; (c) Praça Maria João - Figueira lluminação alta; (d) Praça João Bandeira - iluminação baixa
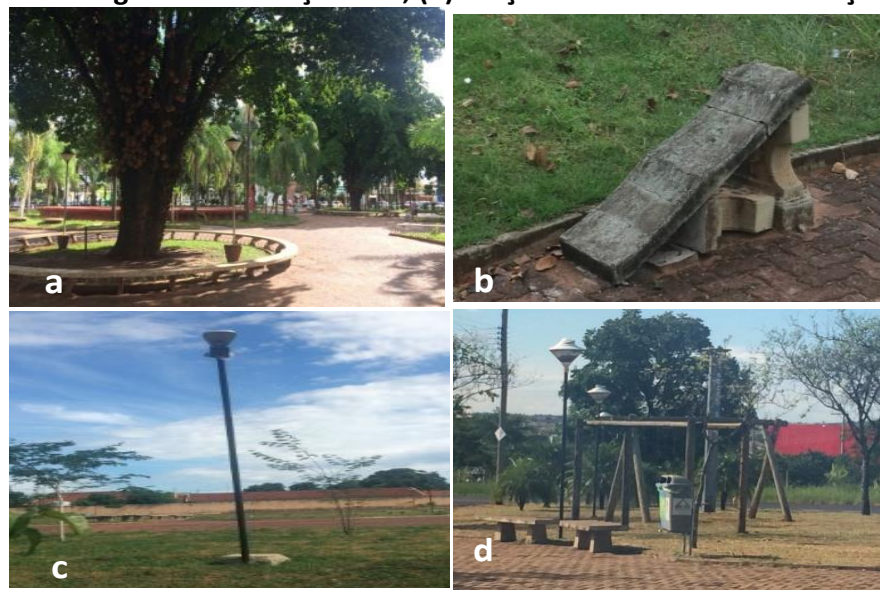

Apenas 11 praças possuem lixeiras (46\%), sendo, na sua maioria, de polipropileno e em bom estado de conservação. Apresentam-se bem localizadas e distribuídas, além de possibilitarem a coleta seletiva dos resíduos. (Figura 3a). Em uma das praças (João Guzzo), as lixeiras são de concreto estando atualmente sem manutenção (Figura $3 b$ ).

Figura 3: (a) Praça São Bento - lixeiras de coleta seletiva (b) Praça João Guzzo - lixeiras de concreto sem manutenção
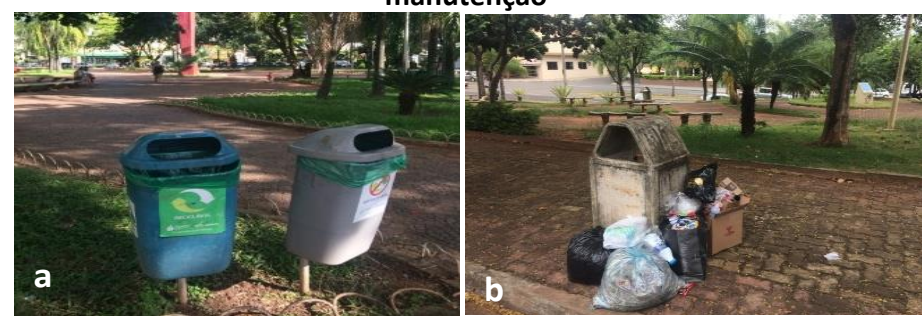

Quanto a presença de sanitários, somente a praça São Bento os possui. Seu estado de conservação é precário, e por serem subterrâneos e sem a presença de um funcionário, não apresentam segurança aos usuários, não possuindo também acessibilidade (Figuras 4a e 4b). 


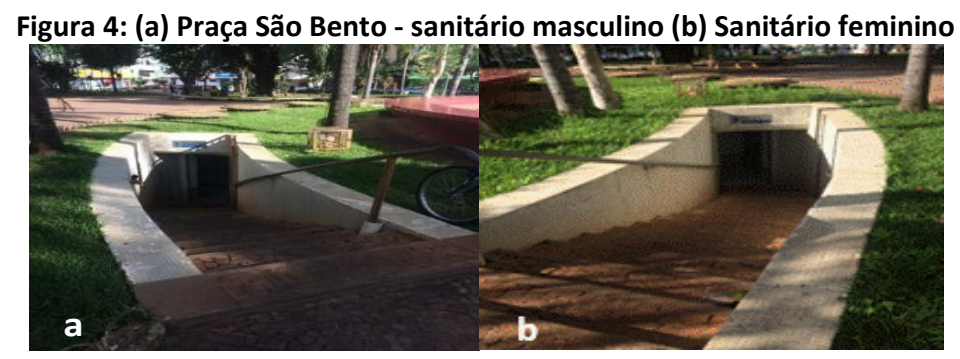

Em três praças (São Bento, Gracinda Lopes Mechi e São Judas Tadeu) existe a presença de telefones públicos em bom estado de conservação, sendo, porém, em uma delas (Gracinda Lopes Mechi) o único elemento presente, além de não haver planejamento paisagístico e acessibilidade, apenas vegetação espontânea (Brachiaria spp).

Duas praças (Augusto Piacenti e São Judas Tadeu) possuem bebedouros de alvenaria com revestimento cerâmico antigo e torneiras, porém, sem refrigeração. O estado de conservação é adequado, assim como sua acessibilidade (Figuras 5 a e 5b).

Figura 5: (a) Praças Augusto Piacenti (b) Praça São Judas Tadeu - bebedouros de alvenaria revestido em cerâmica, com torneira e sem refrigeração

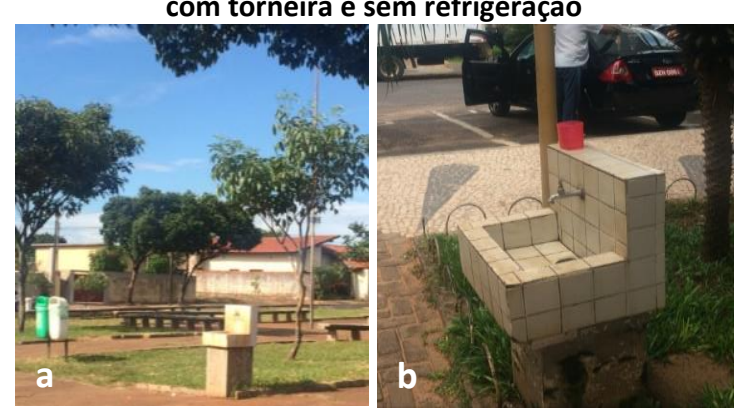

Existem 16 praças com pavimentação (67\%), destas, 50\% são de piso intertravado, $19 \%$ de piso cimentado, $12,5 \%$ de pedra portuguesa, $12,5 \%$ sextavado e $6,3 \%$ de concreto estampado, todas com boa conservação e acessibilidade (Figuras 6a e 6b).

Os traçados dos caminhos são adequados para a caminhada dos usuários, assim como sua largura, desenho e estética, harmonizando-se com a paisagem. 


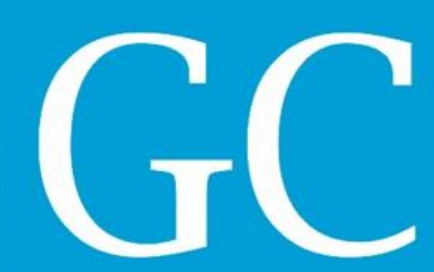

Revista Nacional de

Figura 6: a) Praça São Bento - piso pedra portuguesa (b) Praça Irmã Mạ Ignez-Mazzero - piso intertravado

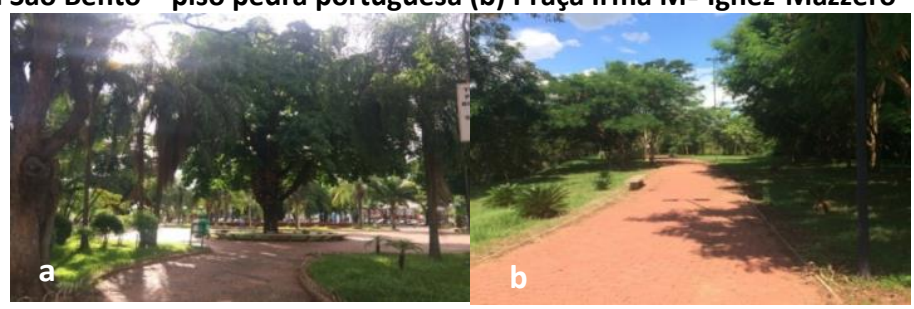

Três praças (Praça São Bento, Praça Rotary e Praça João Guzzo) possuem elementos considerados obras de arte (Figuras 7 a, b, c e d), ou seja, totem, pórticos, espelho de água, fonte iluminada, busto escultural e placa comemorativa.

Figura 7: (a) Praça São Bento - totem com relógio (b) Praça São Bento - espelho de água e fonte iluminada (c) Praça São Bento - pórtico japonês (d) Praça Rotary - busto escultural

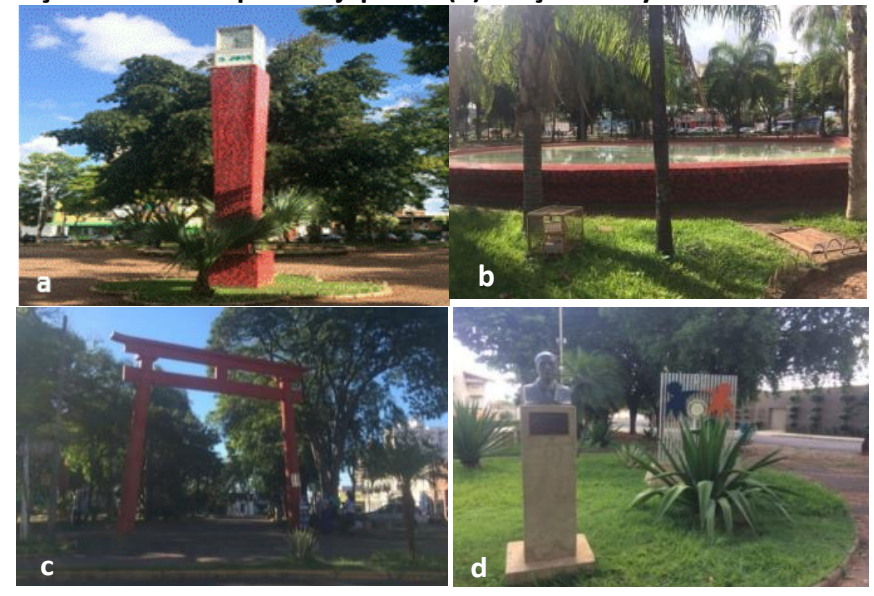

Apenas duas praças (São Bento e São Judas Tadeu) possuem estacionamento com quantidade adequada de vagas, conservação, segurança e acessibilidade, não possuindo, em uma delas, sombreamento para os veículos (São Judas Tadeu).

Somente a Praça São Bento possui ponto de táxi coberto com telefone. Havendo em três praças (José Sanchez Peres Junior, São Judas Tadeu e Helena Maria Arena dos Santos) parada de ônibus, duas delas com abrigo de proteção de estrutura metálica com banco para descanso e uma de eucalipto com cobertura em telhas cerâmicas (Figuras 8 a, b e c). 


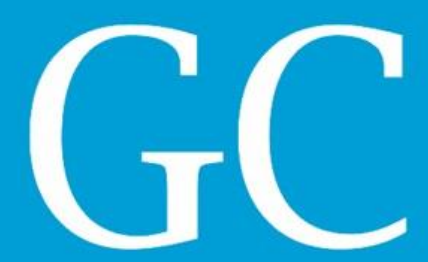

Revista Nacional de

Figura 8: (a) Praça José Sanches Peres - ponto de ônibus de eucalipto tratado e cobertura em telhas cerâmicas (b) Praça Helena Maria Arena dos Santos - ponto de ônibus sem cobertura (c) Praça São Judas Tadeu - ponto de ônibus com cobertura de proteção e banco metálico

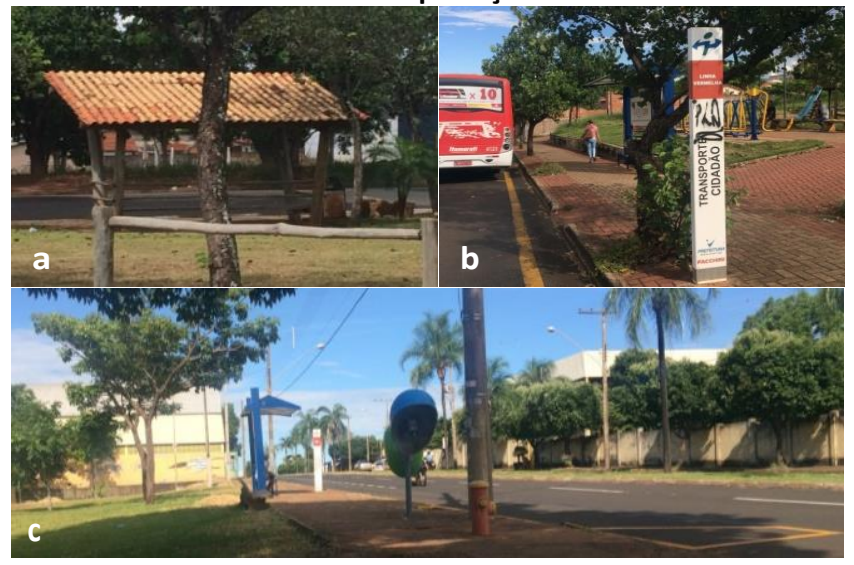

Em relação aos equipamentos para exercícios físicos, somente três praças (Augusto Piacenti, Maria de Jesus Gimenez Hernandez e Helena Maria Arena dos Santos) os possuem, ou seja, $12,5 \%$ do total estão equipadas com academia ao ar livre, com diversos aparelhos metálicos em bom estado de conservação e elevada taxa de utilização por pessoas de diferentes faixas etárias (Figuras 9 a, b e c).

Figura 9: (a) Praça Augusto Piacenti, (b) Praça Maria de Jesus Gimenez Hernandez (c) Praça Maria Helena Arena dos Santos - com equipamentos físicos

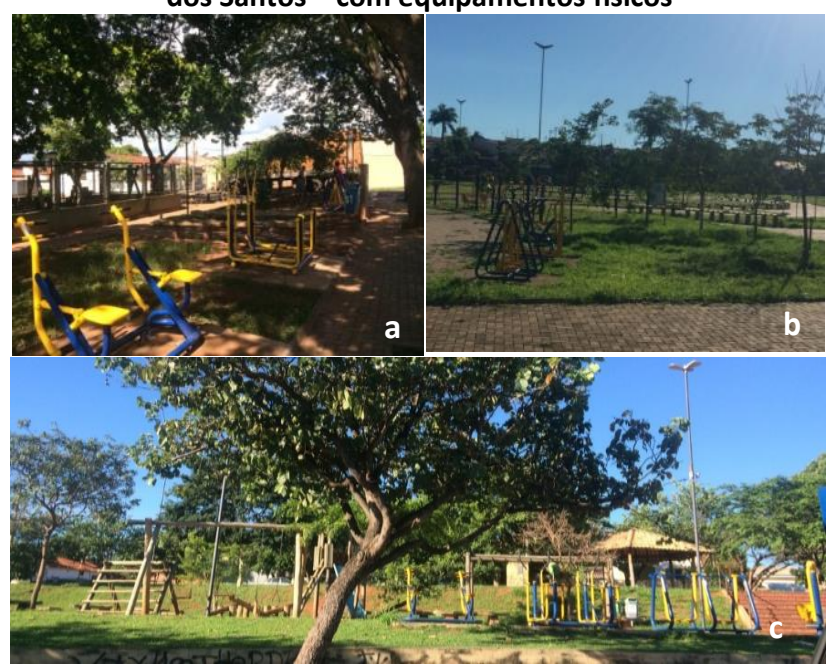

Já os equipamentos de recreação infantil estão presentes em quatro praças (Augusto Piacenti, Maria de Jesus Gimenez Hernandez, João Bandeira e Helena Maria Arena dos Santos), sendo em $75 \%$ delas de eucalipto tratado, com manutenção constante, acessíveis e seguros (Figuras 10 b, c e d), havendo também os de estrutura metálica (Figura 10 a). 


\section{Revista Nacional de}

Nas 24 praças foram contabilizadas 1.168 árvores de 64 espécies (37 nativas e 27 exóticas), sendo $75,5 \%$ nativas e o restante, $19,2 \%$ exóticas e 5,3\% exóticas invasora, ou seja, originárias de outros países.

A vegetação nativa é um dos elementos mais importantes para o equilíbrio da biodiversidade e se desenvolvem naturalmente no ambiente do qual são originárias e a qual estão adaptadas. De acordo com Ziller (2012), o conceito de plantas nativas independe de divisas políticas, sendo os limites de distribuição das espécies impostos por condições físicas, geográficas e climáticas. Com isso, é muito importante que toda e qualquer espécie vegetal antes de ser cultivada, deva ser investigada quanto sua origem, a fim de evitar uma crise no ambiente no qual se deseja plantar.

As espécies exóticas ocorrem em ambientes fora de sua distribuição natural, ou seja, não são originárias do local onde habitam, sendo as exóticas invasoras de alto potencial de proliferação, resistência para sobreviver em ambientes diferentes do seu original, rápido crescimento e assim, passam a representar uma ameaça eminente às espécies nativas, já que não possuem predadores e podem se multiplicar e degradar completamente o ecossistema (PIVELLO, 2011).

O impacto gerado por elas é tão grave, que de acordo Chapin et al. (2000) e Simberloff et al. (2013), as espécies invasoras são consideradas a segunda maior causa de ameaça à perda de biodiversidade mundial, ficando apenas atrás da destruição dos habitats.

No Brasil não é diferente, as espécies invasoras estão dominando de forma perigosa os ambientes naturais e assumindo grande responsabilidade nos casos de perda de biodiversidade dos biomas e de seus recursos genéticos, promovendo a completa mudança nas características naturais das paisagens (MAGALHÃES; FORSBERG, 2016). 


\section{Revista Nacional de}

Tabela 3: Praças do quadrante SE de Votuporanga-SP, bairros, número de espécies arbóreas nativas, exóticas e exóticas invasoras e suas porcentagens, 2017

\begin{tabular}{|c|c|c|c|c|c|c|c|c|c|c|}
\hline No & Nome da Praça & Área $\left(\mathrm{m}^{2}\right)$ & 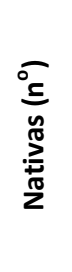 & 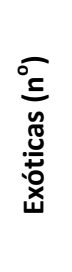 & 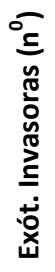 & 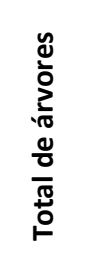 & 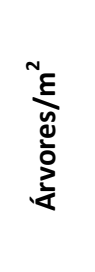 & 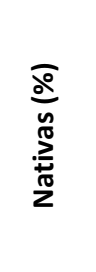 & 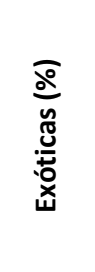 & 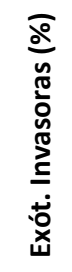 \\
\hline 1 & São Bento & $12.077,98$ & 86 & 26 & 0 & 112 & 0,009 & 76,8 & 23,2 & 0,0 \\
\hline 2 & Rotary & 389,82 & 8 & 4 & 0 & 12 & 0,031 & 66,7 & 33,3 & 0,0 \\
\hline 3 & Augusto Piacentini & $1.270,95$ & 19 & 9 & 0 & 28 & 0,022 & 67,9 & 32,1 & 0,0 \\
\hline 4 & Gracinda Mechi & $2.509,04$ & 24 & 3 & 0 & 27 & 0,011 & 88,9 & 11,1 & 0,0 \\
\hline 5 & João Fonseca & $1.036,00$ & 5 & 9 & 2 & 16 & 0,015 & 31,3 & 56,3 & 12,5 \\
\hline 6 & Irmã Mazzero & $9.314,90$ & 107 & 12 & 39 & 158 & 0,017 & 67,7 & 7,6 & 24,7 \\
\hline 7 & Daniel Dorado & 450,94 & 16 & 6 & 0 & 22 & 0,049 & 72,7 & 27,3 & 0,0 \\
\hline 8 & Orlando Serão & 210,29 & 0 & 6 & 6 & 12 & 0,057 & 0,0 & 50,0 & 50,0 \\
\hline 9 & Bráulio Silva & 90,68 & 1 & 13 & 3 & 17 & 0,187 & 5,9 & 76,5 & 17,6 \\
\hline 10 & Abadia Abdo & $2.278,67$ & 3 & 6 & 0 & 9 & 0,004 & 33,3 & 66,7 & 0,0 \\
\hline 11 & Eugênio Galetti & 532,00 & 0 & 0 & 0 & 0 & 0,000 & 0,0 & 0,0 & 0,0 \\
\hline 12 & João Guzzo & $1.812,08$ & 16 & 20 & 0 & 36 & 0,020 & 44,4 & 55,6 & 0,0 \\
\hline 13 & Adilson Ribeiro & $11.377,06$ & 0 & 0 & 0 & 0 & 0,000 & 0,0 & 0,0 & 0,0 \\
\hline 14 & Maria Hernandez & $12.911,19$ & 70 & 9 & 0 & 79 & 0,006 & 88,6 & 11,4 & 0,0 \\
\hline 15 & Arcidio Belini & $2.826,66$ & 105 & 4 & 4 & 113 & 0,040 & 92,9 & 3,5 & 3,5 \\
\hline 16 & João de Carvalho & $6.271,96$ & 144 & 0 & 0 & 144 & 0,023 & 100,0 & 0,0 & 0,0 \\
\hline 17 & João Toloni & $1.355,95$ & 124 & 12 & 0 & 136 & 0,100 & 91,2 & 8,8 & 0,0 \\
\hline 18 & Arcidio Belini Jr & $4.951,30$ & 118 & 0 & 6 & 124 & 0,025 & 95,2 & 0,0 & 4,8 \\
\hline 19 & Carmen Molleis & $5.708,76$ & 16 & 34 & 0 & 50 & 0,009 & 32,0 & 68,0 & 0,0 \\
\hline 20 & José Sanches & $2.124,33$ & 10 & 10 & 2 & 22 & 0,010 & 45,5 & 45,5 & 9,1 \\
\hline 21 & São Judas Tadeu & $3.690,06$ & 0 & 15 & 0 & 15 & 0,004 & 0,0 & 100,0 & 0,0 \\
\hline 22 & João Bandeira & $1.352,52$ & 0 & 13 & 0 & 13 & 0,010 & 0,0 & 100,0 & 0,0 \\
\hline 23 & Helena dos Santos & $2.408,82$ & 10 & 13 & 0 & 23 & 0,010 & 43,5 & 56,5 & 0,0 \\
\hline 24 & Diacuí & 279,79 & 0 & 0 & 0 & 0 & 0,000 & 0,0 & 0,0 & 0,0 \\
\hline \multicolumn{2}{|c|}{ Total $\left(n^{\circ}\right)$} & $87.231,75$ & 882 & 224 & 62 & 1.168 & 0,013 & - & - & - \\
\hline \multicolumn{2}{|c|}{ Média (\%) } & & - & - & - & - & & 75,5 & 19,2 & 5,3 \\
\hline
\end{tabular}

Ainda de acordo com a Tabela 3, verifica-se de forma até surpreendente, que existe uma elevada porcentagem de espécies nativas nas praças do quadrante $\mathrm{NE}$, o que provavelmente é decorrência da presença natural destas árvores, visto que muitas não foram projetadas e nem arborizadas, sendo apenas fragmentos verdes deixados com sua vegetação espontânea. Nas demais, por haver um "planejamento", optou-se por espécies exóticas. Outro aspecto analisado, é a presença de muitas espécies pioneiras dentre as utilizadas. Sabe-se que as pioneiras, que possuem vida relativamente curta, até 10 anos, morrem deixando clareiras, aonde os capins e as formigas se proliferam, dificultando a emergência ou o plantio de outras árvores. Assim, nestes locais o ideal seria o enriquecimento com espécies não pioneiras.

Nas praças mais antigas da cidade, como a Praça São Bento e a Praça Augusto Piacenti, a arborização se mostra harmoniosa, com boa cobertura vegetal havendo árvores adultas e novas, ocorrendo assim um adequado processo de sucessão induzida e formando extratos 


\section{Revista Nacional de}

arbóreos. Em praças mais novas, existe um bom número de árvores, mas com pouca cobertura devido ao porte pequeno. Espera-se que estas praças tenham boa cobertura vegetal no futuro, sejam bem equipadas e que passem a ser uma opção de lazer para a população.

Diante dessas análises pode-se sugerir para a recuperação da finalidade primordial desses espaços públicos algumas ações:

- $\quad$ Plano de recuperação dos equipamentos existentes, bem como identificação dos mais utilizados e desativação dos que não forem adequados ao uso da população do entorno;

- Identificação dos anseios da população adjacente quanto a possíveis equipamentos a serem implantados que estimulem a frequência e o uso desses espaços;

- $\quad$ Plano de conservação das praças a ser promovido pela Prefeitura Municipal;

- Campanha de educação a ser promovida pela Prefeitura de forma a conscientizar a população para a conservação desses espaços e seus equipamentos como bem comum e incentivo para o seu uso;

- $\quad$ Plano de plantio de espécies arbóreas nativas, principalmente não pioneiras, a fim de aumentar as áreas de sombreamento, melhorando o microclima e substituindo a longo prazo as espécies inadequadas;

- $\quad$ Cautela e planejamento no plantio de espécies exóticas, principalmente as exóticas invasoras.

\section{CONCLUSÃO}

As praças do quadrante SE de Votuporanga/SP são de extrema importância para a população adjacente, porém, a maioria carece de infraestrutura e necessita de investimentos na conservação e manutenção dos seus elementos arquitetônicos e paisagísticos, além de não promover o lazer aos usuários de forma eficaz e satisfatória. Quanto às árvores, apesar de $75,5 \%$ serem nativas, existe a necessidade de um maior número e diversificação de espécies vegetais.

\section{REFERÊNCIAS}

ALCÂNTARA, M. A. R.; VAZQUEZ, G. H. Caracterização paisagística e da frequência de usuários de duas praças centrais de Caraguatatuba/SP. Revista da Sociedade Brasileira de Arborização Urbana. Piracicaba/SP, v. 10, n. 3, p. 38-59, 2015. Disponível em: <http://www.revsbau.esalq.usp.br/teste/ojs-

2.3.7/index.php/REVSBAU/article/view/464>. Acesso em: 20 dez. 2017.

BRASIL. Constituição da República Federativa do Brasil - 1988: texto constitucional promulgado em 5 de outubro, com as alterações determinadas pelas Emendas Constitucionais de Revisão nos 1 a 6/94, pelas Emendas Constitucionais nos 1/92 a 91/2016 e pelo Decreto Legislativo no 186/2008, Brasília: Senado Federal, Coordenação de Edições Técnicas, 2016, 496 p.

CHAPIN, F. S. et al. Consequences of changing biodiversity. Nature, n. 405, p. 234-242, 2000. 


\section{Revista Nacional de}

DE ANGELIS, B. L. D.; CASTRO, R. M. DE; DE ANGELIS NETO, G. Metodologia para levantamento, cadastramento, diagnóstico e avaliação de praças no Brasil. Engenharia Civil, Guimarães, Portugal, v. 20, p. 57-70, 2004.

DE ANGELIS, B. L. D. et al. Praças: história, usos e funções. Maringá: EDUEM, 2005.

GOOGLE MAPS. Votuporanga, Estado de São Paulo. [Internet], 2017. Disponível em: <https://acontecimentosdodiablog.files.wordpress.com/2017/08/8-de-agosto-e28093-mapa-de-localizac3a7c3a3oe28094-votuporanga-sp-e28094-80-anos-em-2017.jpg?w=328\&h=205>. Acesso em: 10 dez. 2017.

IBGE - Instituto Brasileiro de Geografia e Estatística - Cidades. Panorama Votuporanga. [Internet], 2017. Disponível em: <https://cidades.ibge.gov.br/brasil/sp/votuporanga/panorama>. Acesso em: $10 \mathrm{dez} .2017$.

MAGALHÃES, L. C. S.; FORSBERG, M. C. S. Espécies exóticas invasoras: caracterização e ameaças aos ecossistemas. Scientia Amazonia, v. 5, n. 1, p. 64-65, 2016. Disponível em: <www.scientia-amazonia.org>. Acesso em: 10 jan. 2018.

MARX, M. Cidade brasileira. São Paulo: Melhoramentos, 1980.

MINAYO, M. C. S.; HARTZ, Z. M. A.; BUSS, P. M. Qualidade de vida e saúde: um debate necessário. Ciênc. saúde coletiva, Rio de Janeiro, v. 5, n. 1, p. 7-18, 2000. Disponível: <http://dx.doi.org/10.1590/S1413$81232000000100002>$. Acesso em: 12 dez. 2017.

PIVELLO, V. R. Invasões biológicas no cerrado brasileiro: efeitos da introdução de espécies exóticas sobre a biodiversidade. Ecologia. Info, v. 33, p. 20 - 42, 2011.

SIMBERLOFF, D. et al. Impacts of biological invasions: what's what and the way forward. Trend in Ecology and Evolution, v. 28, n.1, p. 58- 66, 2013.

SOUZA, M. C. C.; AMORIM, M. C. C.T. A problemática ambiental e o verde urbano. Periódico Técnico e Científico Cidades Verdes, v. 1, n. 1, p. 29-43, 2013.

VOTUPORANGA. Plano de Desenvolvimento Integrado de Votuporanga (PDI), GPI. Diagnóstico e Lei de Zoneamento, Uso e Ocupação do Solo e pranchas temáticas (diagnóstico e diretrizes). Votuporanga, 1971.

VOTUPORANGA. Lei complementar no 16, de 20 de dezembro de 2006. Dispõe sobre a instituição do Plano Diretor Participativo do Município de Votuporanga, cria o Conselho da Cidade e dá outras providências. Disponível em: <http://consulta.siscam.com.br/camaravotuporanga/arquivo?ld=56112>. Acesso em: 09 jan. 2018.

VOTUPORANGA. Prefeitura do Município de Votuporanga. Localização - Dados geográficos. Votuporanga, 2018. Disponível em: <http://www.votuporanga.sp.gov.br/n/publicacao/?x=turista\&p=201367144655-localiza--0>. Acesso em: 15 jan. 2018.

ZILLER, S. R. Conceitos sobre espécies exóticas invasoras. Instituto Hórus, 2012. Disponível em: <http://www.ipef.br/eventos/2012/controle/Aula_1-Conceitos.pdf>. Acesso em: 19 jan. 2018. 